\title{
Studying a 2 millennia old bronze kettle using easily accessible characterization techniques
}

\author{
Marta Kotlar ${ }^{1}$, Nives Matijaković Mlinarić², Vladan Desnica ${ }^{3}$ and Katarina Marušić ${ }^{*}$ (])
}

\begin{abstract}
A bronze kettle dating from the 1st to 2 nd century was found in a riverbed of the Kupa river in Croatia. After excavation it spent another 50 years in a depot of a museum in atmospheric conditions prior to starting the conservation treatment and our studies. A study on the surface layers development was performed to determine the whereabouts of the object through its history. This study is a demonstration of how such analysis can be used to reconstruct what the object went through during its life span. Samples taken from the kettle were observed by optical and scanning electron microscopy (SEM), and analysed by X-ray fluorescence (XRF), X-ray energy dispersive spectroscopy (EDS) and Fourier transform infrared spectroscopy (FTIR).

It was determined that the kettle is made of low-tin bronze, with low amounts of iron, aluminium, calcium and nickel. While being in the riverbed malachite formed on the kettle. After longer exposure to the river Si-oxides and $\mathrm{CaCO}_{3}$ formed on the surface of the kettle, over malachite. It was shown that the kettle probably had a ferrous alloy handle which degraded and disappeared in time. After excavation, the kettle came again in an oxygen-enriched atmosphere and formed new surface layers over the malachite layer. As the museum the kettle has been kept in since excavation is set in a highly industrial area sulphur compounds have been formed on the surface.
\end{abstract}

Keywords: Ancient bronze, Corrosion products, Patina, Surface layers

\section{Introduction}

Objects made of copper and its alloys are often covered by layers of corrosion products called patina. The characteristic green-blue patina colour is caused by the $\mathrm{Cu}(\mathrm{II})$ ion in compounds forming the outer patina layer, such as brochantite $\left(\mathrm{Cu}_{4} \mathrm{SO}_{4}(\mathrm{OH})_{6}\right)$, antlerite $\left(\mathrm{Cu}_{3}\left(\mathrm{SO}_{4}\right)(\mathrm{OH})_{4}\right)$ or atacamite $\left(\mathrm{Cu}_{2} \mathrm{Cl}(\mathrm{OH})_{3}\right)$. The $\mathrm{Cu}$ (II) ion acts as a colour forming ion, and is part of all compounds in the outer patina layer. Patina can be darkened by presence of copper sulphides or lead, lightened by lead carbonate or tinoxide and reddened by an underlying layer of cuprite,

\footnotetext{
*Correspondence: kmarusic@irb.hr

${ }^{4}$ Ruđer Bošković Institute, Division of Materials Chemistry, Radiation Chemistry and Dosimetry Laboratory, Bijenička c. 54, Zagreb HR-10000 Croatia

Full list of author information is available at the end of the article
}

$\mathrm{Cu}_{2} \mathrm{O}$ [1]. It is hard to distinguish different compounds by mere observation of the patina colour [2]. A large number of studies have shed light on different conditions and effects influencing formation of a variety of copper and bronze patinas [1,3-5]. For example, when copper corrosion occurs during burial usually first an inner layer of copper(I) compounds forms next to the metal surface and on top of it outer layers of green or blue copper(II) compounds, consisting of one or more copper(II) salts. Presence of carbon dioxide in humid closed spaces can lead to formation of copper(II) carbonate hydroxides like malachite or azurite [6]. It is also known that after sudden or drastic changes in environment, e.g. after excavation corrosion is restarted or accelerated on bronze objects which leads to formation of new layers of corrosion products [7]. In museums or museum depots harmful gaseous pollutants can be present, forming a variety of

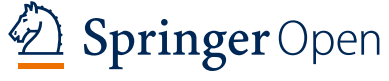

(c) The Author(s) 2021. This article is licensed under a Creative Commons Attribution 4.0 International License, which permits use, sharing adaptation, distribution and reproduction in any medium or format, as long as you give appropriate credit to the original author(s) and the source, provide a link to the Creative Commons licence, and indicate if changes were made. The images or other third party material in this article are included in the article's Creative Commons licence, unless indicated otherwise in a credit line to the material. If material is not included in the article's Creative Commons licence and your intended use is not permitted by statutory regulation or exceeds the permitted use, you will need to obtain permission directly from the copyright holder. To view a copy of this licence, visit http://creativeco mmons.org/licenses/by/4.0/. The Creative Commons Public Domain Dedication waiver (http://creativecommons.org/publicdomain/ zero/1.0/) applies to the data made available in this article, unless otherwise stated in a credit line to the data. 
corrosion products such as nitrates, sulphates, sulphides, oxides, formates, acetates, and salts of higher carboxylic acids [8]. If one understands the relationship and interaction between environments metals are exposed to and the formation and stability fields of corrosion products on metals, one may be able to reconstruct environmental conditions surrounding the object in the past. This information should provide investigators with the possibility of writing the biography of ancient metal artefacts [5], i.e. by studying the corrosion products layering and composition it is possible to reconstruct the whereabouts of an object through its history. The conclusions obtained from such studies are valuable both for the person performing the conservation treatment as well as for art historians.

There are numerous objects made of copper alloys that were found with no known history. The problem is that metals do not possess physical properties that can be expressed as a function of time and thus metallic artefacts cannot be directly dated. There are different approaches for authentication of ancient metals [9], but still the history of the artefacts is often not clear. When working with objects of historical or cultural importance it is possible to obtain samples of corrosion products from the artefact during the restauration treatment, but it is not possible to do studies that would use any destructive methods on the object itself. There are standard techniques used for analysing corrosion products like $\mathrm{X}$-ray radiography, or $\mathrm{X}$-ray diffraction which is useful for validating hypothetical presence of unusual products. Yet, many objects are kept in small museums where limited instrumentation is available. Also, often the owners of an object of interest do not permit large interventions. This is the reason why conservators are frequently left to their own resourcefulness upon examination of an interesting object to obtain the necessary data through an alternative approach and limited resources. This work presents an effort of a joined collaboration of conservators and scientists to characterize surface layers and corrosion products of an ancient bronze artefact using only elemental analysis in combination with Fourier Transform Infrared Spectroscopy. It shows how it is still possible to obtain very useful data despite common limitations if an appropriate collaboration of curators and scientists is established.

A bronze kettle dating from the 1st to 2nd century, Roman Empire period was found in a riverbed in the place of the Roman Empire city Siscia in Croatia. After excavation it spent another 60 years in a depot of a museum in highly polluted atmospheric conditions prior to starting the conservation treatment and our studies. The item was received in a very bad condition and was covered with various corrosion products and remains of sand trapped in the corrosion products. Upon observing the exact state of the object, it was obvious that these very diverse surface layers were very interesting, not only for their different structure and colours, but also for their complexity. We intended to study which corrosion products had been created on the surface of the object, considering the environment in which the object was exposed to, as well as the chronological order of the corrosion products formation. In order to do so different analysis and instrumentation were used on a selected number of samples.

\section{Materials and methods Materials}

In the 1960s during dredging of the Kupa river in Sisak, an industrial city located in central Croatia, a large group of objects was found, among which was the object of our investigations. A bronze kettle $22 \mathrm{~cm}$ high and $22 \mathrm{~cm}$ wide dating from the 1st to 2nd century, Roman Empire period, probably from the Roman Empire city Siscia spent over a millennium in the riverbed. After excavation, the kettle was stored in the depot of the Sisak Municipal Museum and was not processed until 2018 when it was sent for conservation-restoration treatment to the Art and Restoration Department of University of Dubrovnik, Workshop for conservation and restoration of metal. Prior to performing the complete conservation treatment different surface layers were visually distinguished and sampled. The investigations were performed on these samples.

\section{Sampling}

When the kettle was received at the Workshop for restoration treatment it was in a very bad condition and covered with various corrosion products and remains of sand trapped in the corrosion products. According to the museum inventory form the kettle is made by the embossing technique. No X-ray radiography or crosssectional study was possible, thus after visual examination, six samples were taken from the kettle for further analysis. Two samples were fragments of the kettle which broke off while manipulating the object due to its poor condition and metal fatigue of the thin bronze sheet. Since both samples were observed as metal core, they could be used for determining the composition of the alloy the object is made from. They were covered with corrosion products and analysed as Samples 1 and 2 . Four samples (named Samples 3 to 6) were taken from the surface of the object as presented in Fig. 1. Each sample seemed to have a different surface layer based on the difference in colour and structure. These samples were scratched from the surface using scalpel during mechanical cleaning in conservation interventions. 


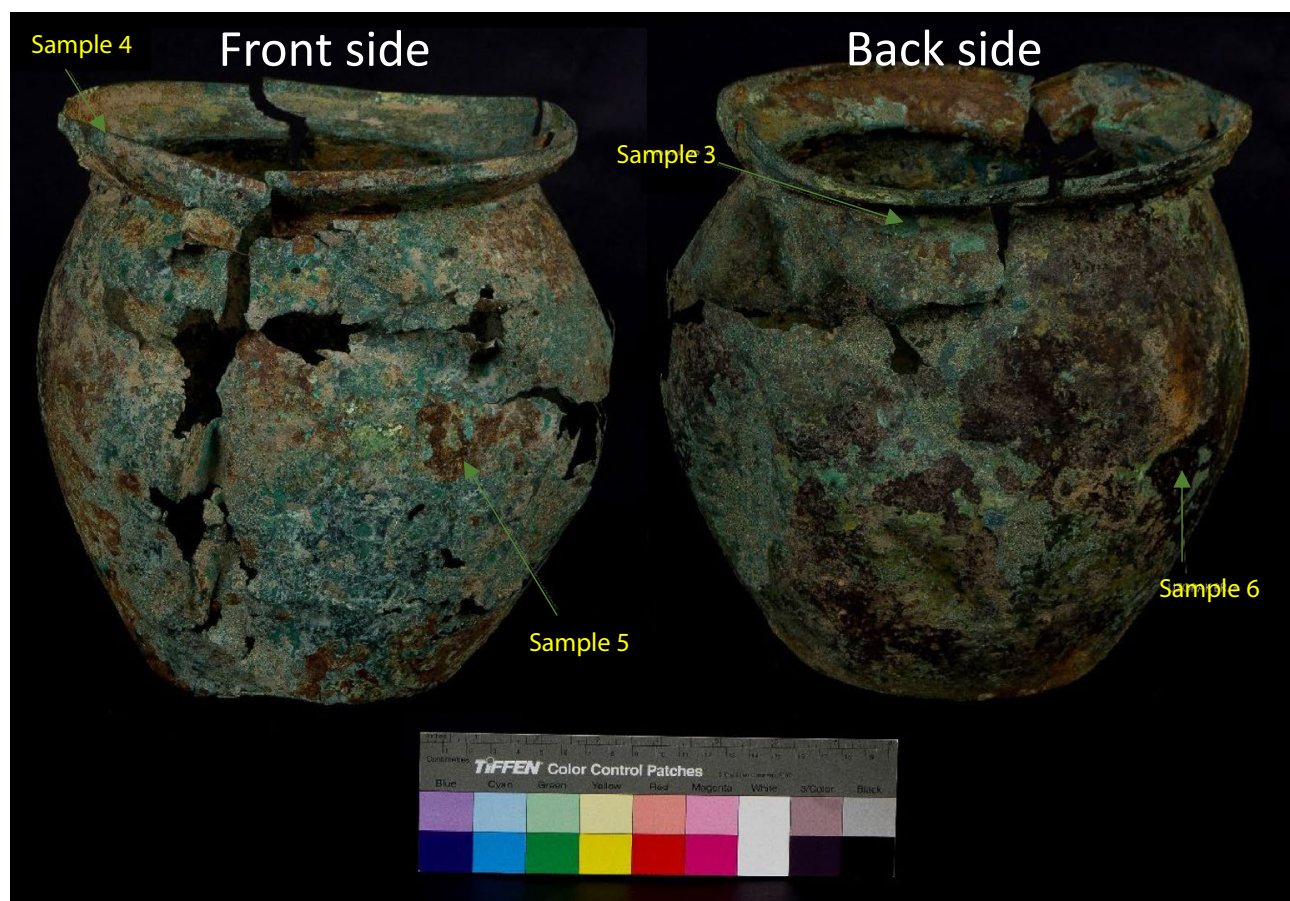

Fig. 1 Image of the bronze kettle and the surface layers'sampling positions

\section{Methods}

\section{Observation by optical microscopy}

Once the samples were collected from the kettle they were all observed by a digital microscope Dino-Lite AM4113ZT under $60 \mathrm{x}$ and $240 \mathrm{x}$ magnification, prior to any analyses.

\section{$X$-ray fluorescence (XRF) analysis}

The samples were investigated using a portable XRF instrument, which was developed at the Laboratory of the Academy of fine arts in Zagreb. It consists of a 50-kV Rh transmission excitation tube (Moxtek, USA) and a Peltier cooled silicon drift detector (Amptek, USA) with energy resolution of $145 \mathrm{eV}$ at the $\mathrm{Mn} \mathrm{K \alpha}$ excitation line. Depending on the analytical needs, the device can provide either mili or micro X-ray beam for sample excitation, by employing a motorized collimator interchanger to switch between a pinhole collimator (spot size ca. $1.5 \mathrm{~mm}$ ) and a polycapillary lens (IfG, Germany, spot size ca. $65 \mu \mathrm{m}$ ). The operating parameters for tube voltage and anode current during the measurements were set to $40 \mathrm{keV}$ and $150 \mu \mathrm{A}$, respectively, and the acquisition real time was $100 \mathrm{~s}$. For these measurements the device was used in a micro mode and the diameter of the beam was set to ca. $65 \mu \mathrm{m}$. For easy and reproducible alignment of the sample in front of the X-ray source and the detector, a two-laser beam system is used. The lasers are aligned in such a way that the point of their beam intersection coincides with the cross-point of the X-ray tube and detector axes. On every sample two measurements were made and the results are a combination of the obtained data.

\section{Fourier transform infrared spectroscopy (FTIR) analysis}

Fourier transform infrared spectroscopy (FTIR) was performed using Bruker's Tensor II spectrometer (Bruker Optik GmbH, Ettlingen, Germany) equipped with Attenuated total reflection (ATR) module for checking presence of functional groups on the surface of the samples. FTIR spectra were recorded at room temperature in frequency range $500-4000 \mathrm{~cm}^{-1}$ at $4 \mathrm{~cm}^{-1}$ scan step and total 16 scans per measurement.

\section{Scanning electron microscopy and X-ray energy dispersive spectroscopy (SEM/EDS) analysis}

The samples were also inspected using the JEOL JSM$7000 \mathrm{~F}$ field emission scanning electron microscope (FESEM) equipped with the Oxford Instruments INCA-350 $\mathrm{X}$-ray energy dispersive spectrometer microanalysis system (EDS) at an acceleration voltage of 10 or $15 \mathrm{kV}$ depending on the sample. Computer program Image was used in processing of FE-SEM sample images to obtain particle size distributions. 


\section{Results}

\section{Visual and optical observation of the surface layers}

Figure 2 presents the images of the studied surface samples taken by a digital microscope. The most prevalent corrosion product was greenish in colour. It was observed on various samples, most expressed on Sample 3. Also, on the surface of the object, some other impurities have been trapped in corrosion products and accumulation of materials like sludge stones was observed. Other black, brown, white-yellow and blue layers were also visible on the surface. Some of them covered the surface of the green areas, while some were close to the surface of the metal and degraded the metal until they made holes in the material itself. During removal of the layers, it was observed that the black layers (Sample 6) were partially diluted in distilled water and $96 \%$ ethanol. They were easily removed by mechanical cleaning with a scalpel. Below the black layers was a layer of green corrosion products. The brown products (Samples 4 and 5) strongly adhered to the substrate itself. Under the brown layers, green products existed only in traces and did not have such a uniformly covered surface as was the case under the black layers. The yellow-white layers observed on Sample 4 were powdery and below them there was a layer of partially formed green corrosion products, while in other places a very thin layer of reddish-brown layers was observed.

\section{The elemental composition of the samples determined by XRF}

In order to distinguish the alloying elements from the elements embedded from other sources into the corrosion products X-ray fluorescence measurements were performed on all samples. The results are presented in Table 1 . The results consist of three groups of elements: main elements are the principal elements comprising

\section{Table 1 XRF results obtained on the investigated samples of surface layers}

\begin{tabular}{llll}
\hline Sample & Main elements & Other elements & Trace elements \\
\hline Sample 1 & $\mathrm{Fe} \mathrm{Cu}, \mathrm{Sn}$ & - & $\mathrm{Si}, \mathrm{S}, \mathrm{Ca}, \mathrm{Ni}$ \\
Sample 2 & $\mathrm{Fe}, \mathrm{Cu}, \mathrm{Sn}$ & - & $\mathrm{Al}, \mathrm{Si}, \mathrm{S}, \mathrm{Ti}, \mathrm{Pb}$ \\
Sample 2 & $\mathrm{Cu}$ & $\mathrm{Sn}$ & $\mathrm{Al}, \mathrm{Ca}, \mathrm{Ni}$ \\
cleaned & & & \\
Sample 3 & $\mathrm{Fe}, \mathrm{Cu}, \mathrm{Sn}$ & $\mathrm{Ca}$ & $\mathrm{Si}, \mathrm{S}, \mathrm{Ti}, \mathrm{Mn}$ \\
Sample 4 & $\mathrm{Ca}, \mathrm{Fe}, \mathrm{Cu}$ & $\mathrm{Si}, \mathrm{S}, \mathrm{K}, \mathrm{Ti}$ & $\mathrm{Mn}$ \\
Sample 5 & $\mathrm{Fe}, \mathrm{Cu}$ & $\mathrm{Si}, \mathrm{K}, \mathrm{Ca}, \mathrm{Sn}$ & $\mathrm{Al}, \mathrm{K}, \mathrm{Ti}, \mathrm{Mn}, \mathrm{Zn}, \mathrm{As}$ \\
Sample 6 & $\mathrm{Fe}, \mathrm{Cu}$ & $\mathrm{Ca}$ & $\mathrm{Si}, \mathrm{P}, \mathrm{S}, \mathrm{K}, \mathrm{As}$
\end{tabular}

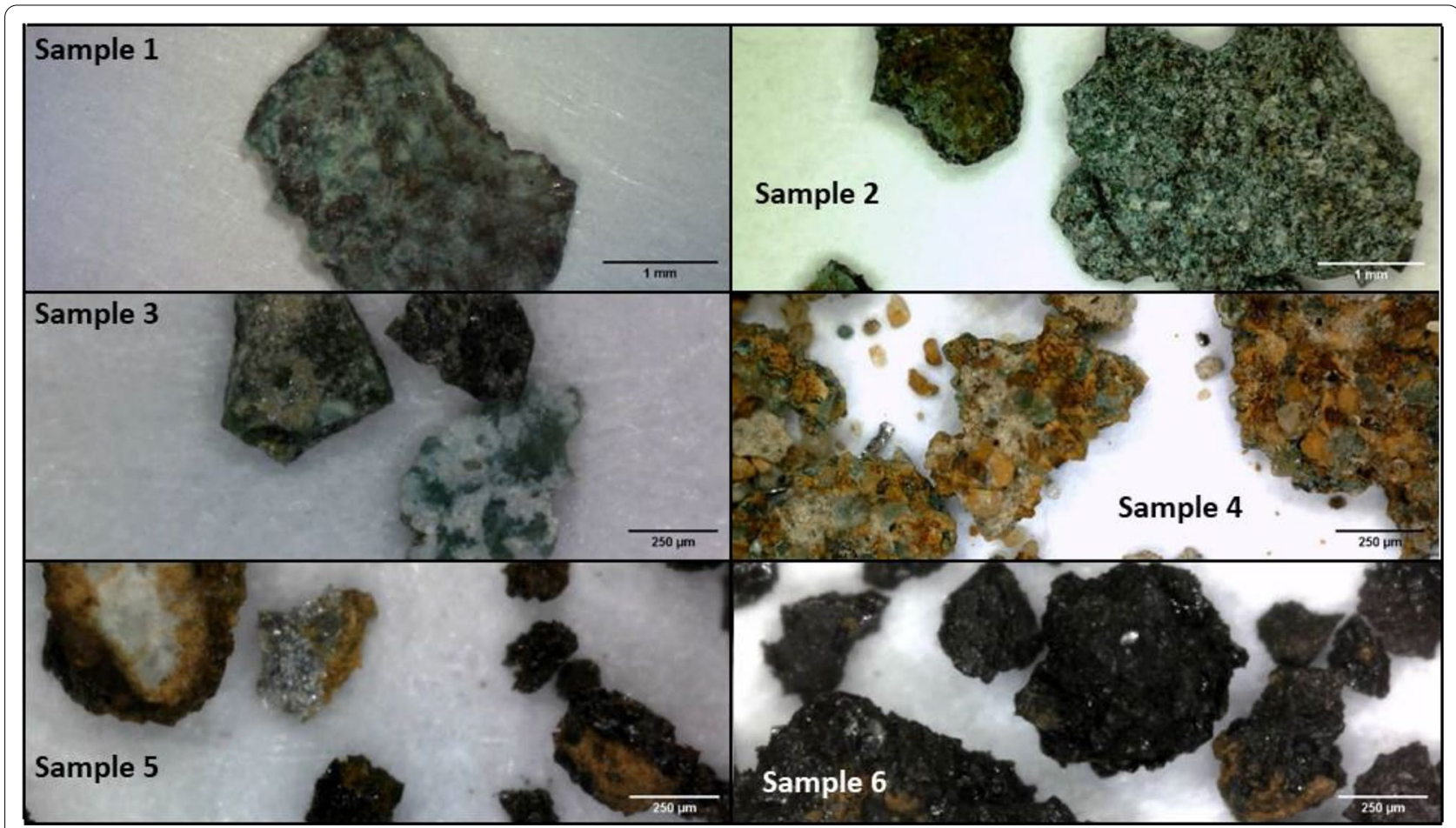

Fig. 2 Images of the examined samples taken by a digital microscope: Samples 1 and 2 which are fragments under $60 x$ and the rest of the samples under 240x magnification 
the bulk of the material with weight concentrations of up to $90 \%$, other elements exhibit concentrations of 0.5 to $10 \%$, while trace elements are present in concentrations below $0.5 \%$. As the XRF analysis was carried out using a portable device in air, with no reference materials and on corroded samples of unequal sizes and shapes, the measurements yielded only semi-quantitative results.

One of the fragments of bronze found discarded in the kettle (Sample 2) was used for analysing the bronze alloy. After performing measurements on the layers covering the surface of the sample, it was cleaned manually in multiple steps. After each cleaning step XRF was performed until a repetitive spectrum was obtained. Upon analysing the obtained spectrum, the approximate concentrations of the present elements were determined: $89.0 \% \mathrm{Cu}$, $9.5 \% \mathrm{Sn}$ with traces of $\mathrm{Fe}, \mathrm{Al}$ and $\mathrm{Ca}$ (below $0.5 \%$ ).

The kettle was found in Kupa which is a karst river. This would explain the presence of calcium from calcium carbonate, $\mathrm{CaCO}_{3}$, in all samples, although calcium was obviously also one of the alloying elements. According to Bilinski [10] the lower part of Kupa river where the kettle was found consist primarily of $\mathrm{SiO}_{2}(81 \%)$, while the other compounds present in Kupa's sediments are $\mathrm{Al}_{2} \mathrm{O}_{3}$, $\mathrm{CaO}, \mathrm{Fe}_{2} \mathrm{O}_{3}, \mathrm{~K}_{2} \mathrm{O}, \mathrm{Na}_{2} \mathrm{O}$ and $\mathrm{MgO}$ and in very small amounts $\mathrm{TiO}_{2}, \mathrm{P}_{2} \mathrm{O}_{5}$ and $\mathrm{MnO}$. Silicon is present either as one of the other elements or as trace elements in all cases. The presence of silicon in large quantities was firstly thought to be an indication of alloying with silicon, but results on the cleaned Sample 2 have shown that silicon is not present in the alloy. Thus, silicon obviously comes from the riverside sediment that has been deposited on the object during the long period of time when the kettle was buried in the river mud.

\section{Surface layer analysis}

IR spectra provide valuable information on the patina composition because IR spectroscopy senses the low crystalline and amorphous fraction and it has an extremely high detection limit for some species commonly found in the patina [11]. FTIR-ATR measurements were performed on all six samples and the results are presented in Fig. 3. The first observation is that the spectra obtained on Samples 2 and 3 are very similar, just as the spectra obtained on Samples 5 and 6. The same observation can be made when looking at the samples with an optical microscope presented in Table 1. All the samples were also analysed with SEM and EDS. The individual results of the samples are presented grouped according to the similarities of the results.

\section{Sample 1}

Sample 1 shows a predominantly greenish surface as can be seen in Fig. 2. SEM analysis of Sample 1 showed a unified structure, while EDS showed a unified composition presented in Fig. 4.

The EDS results show a significant amount of carbon. As explained earlier presence of a form of calcium carbonate is expected. Also presence of malachite, a green carbonate-based corrosion product on copper-based objects buried in a riverbed is common because the environment may be rich in oxygen as well as carbonate/ bicarbonate anions. Carbonate is presented by four normal modes of vibration peaks in FTIR spectra: $v 1 \mathrm{sym}$ metric $\mathrm{C}$-O stretching, $v 2 \mathrm{CO}_{3}$ out-of-plane bending, $v 3$ asymmetric $\mathrm{C}-\mathrm{O}$ stretching mode, and $v 4 \mathrm{O}-\mathrm{C}-\mathrm{O}$ bending (in-plane deformation) mode [4, 10, 12]. In the FTIR spectrum obtained on Sample 1 the bands characteristic
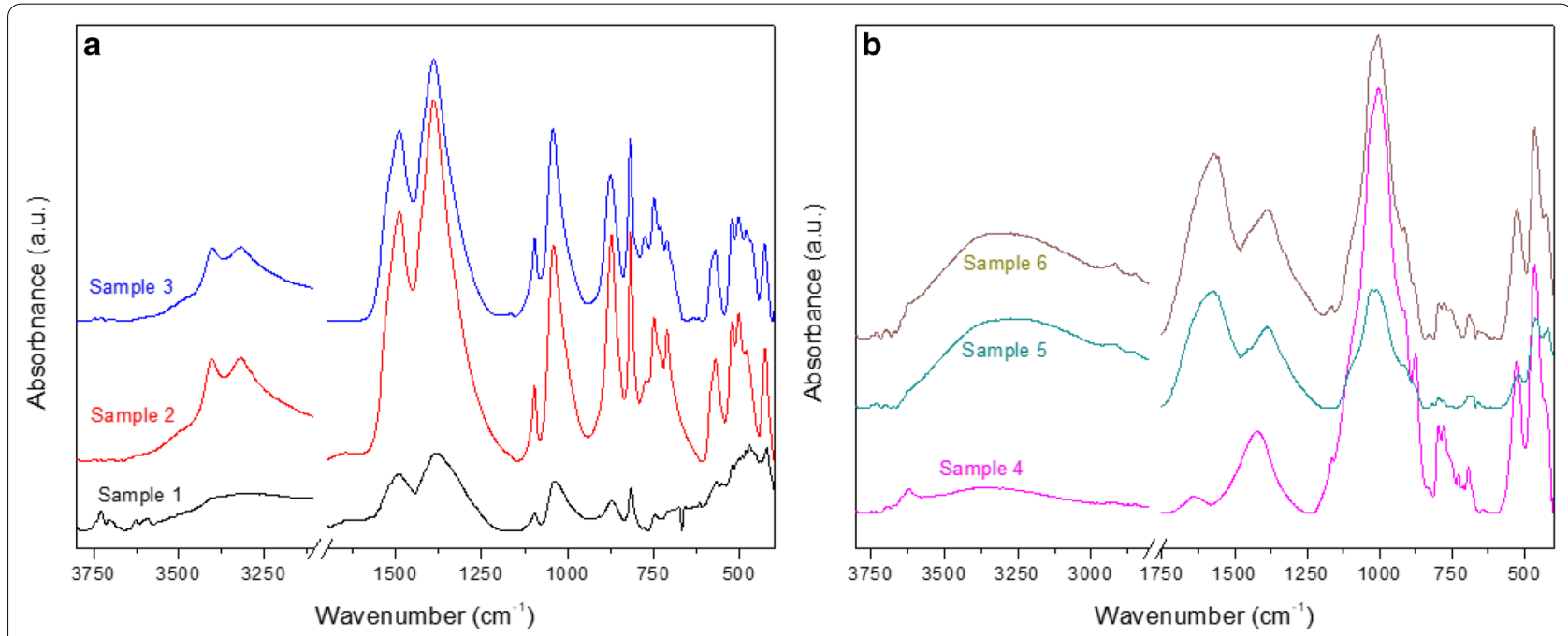

Fig. 3 FTIR-ATR results on the investigated samples of corrosion products 

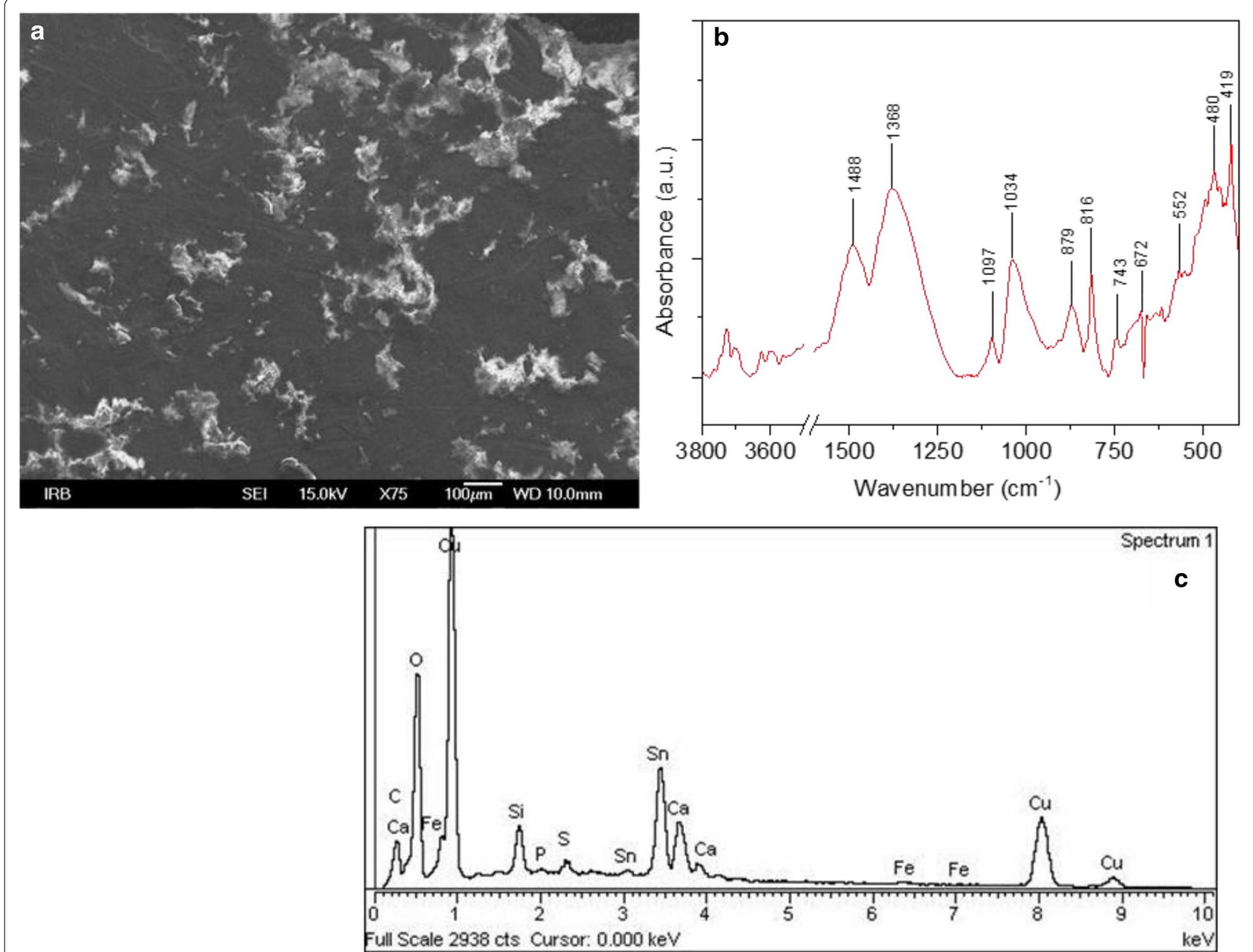

Fig. 4 a SEM image, b FTIR-ATR spectrum and c elemental composition obtained by EDS on Sample 1

for carbonate that are easiest to observe are the two broad bands in the region around $1500-1300 \mathrm{~cm}^{-1}$. The peak at $1488 \mathrm{~cm}^{-1}$ indicates that calcium carbonate is present in the form of vaterite on this sample, since it has been reported that different calcium carbonate phases can be identified using FTIR [13-15]. This is confirmed by the presence of peaks at $743 \mathrm{~cm}^{-1}$ and $879 \mathrm{~cm}^{-1}$ [13]. Presence of malachite, $\mathrm{Cu}_{2} \mathrm{CO}_{3}(\mathrm{OH})_{2}$, is also observed through various peaks. The bands at $\sim 1097$ and $\sim 1034 \mathrm{~cm}^{-1}$ are assigned to the $\mathrm{CO}$ symmetric and asymmetric stretching vibrations. The two bands at 879 and $816 \mathrm{~cm}^{-1}$ are attributed to out of phase and in phase bending modes of carbonate in malachite [16]. The spectrum also shows peaks in the $\mathrm{OH}$ stretching mode region, but although the different basic copper(II) salts developed on copper during corrosion may be identified by IR reflectance spectroscopy, the $\mathrm{OH}$ stretching mode region (above approximately $3000 \mathrm{~cm}^{-1}$ ) cannot be used because of a large overlap observed for different components in the spectra of different compounds [17].

According to both XRF and EDS analysis Sample 1 contains a high amount of tin, actually the highest among the analysed surface samples (21\%). Tin as a corrosion product on antient metals is usually found in the tin(IV)oxide form, i.e. cassiterite, $\mathrm{SnO}_{2}$. Due to its characteristics cassiterite is very difficult to characterize as corrosion product. It is also usually covered by other corrosion products and thus the peaks attributed to $\mathrm{SnO}_{2}$ in a FTIR spectrum are hard to distinguish. The FTIR spectrum obtained on Sample 1 showed different peaks in the fingerprint region presented in Fig. 3b. The spectrum showed a peak at $816 \mathrm{~cm}^{-1}$ which corresponds to the metal-oxide stretching vibrations [18], in this case both to $\mathrm{Sn}-\mathrm{O}$ and $\mathrm{Cu}-\mathrm{O}$ stretching. The peaks at 533 and $480 \mathrm{~cm}^{-1}$ present the bending vibrations [18]. The mineral cassiterite is usually identified in a FTIR spectrum with a peak at around 
$670 \mathrm{~cm}^{-1}$ and a peak at around $550 \mathrm{~cm}^{-1}[19,20]$. Both of these peaks can be observed in the spectrum in Fig. 3b.

EDS showed clear presence of $\mathrm{Si}$ in some form in the sample. Inorganic silicates have $\mathrm{Si}-\mathrm{O}$ bands at $1050-1000 \mathrm{~cm}^{-1}$ (strong) and they also absorb at $540-440 \mathrm{~cm}^{-1}$ (medium). Silica absorbs near $1100 \mathrm{~cm}^{-1}$ (strong), near $800 \mathrm{~cm}^{-1}$ (weak) and near $475 \mathrm{~cm}^{-1}$ (medium). The silica bands overlapped by other peaks are present in the spectra, as well as the band at $\sim 419 \mathrm{~cm}^{-1}$ which is related to the $(\mathrm{O}-\mathrm{Si}-\mathrm{O})$ deformation mode [21, 22].

Both XRF and EDS analysis showed a significant amount of iron in this sample. $\mathrm{Fe}_{2} \mathrm{O}_{3}$ is expected to be present on the surface, if not formed on the bronze, then at least deposited from the river's sediments as explained earlier. The two bands at 533 and $480 \mathrm{~cm}^{-1}$ that are attributed to $\mathrm{SnO}_{2}$ are overlapping bands of $\mathrm{Fe}-\mathrm{O}$ which indicate presence of $\mathrm{Fe}_{2} \mathrm{O}_{3}$ [23].

EDS and XRF analysis also showed that sulphur is present on the surface of Sample 1. The peak that is attributed to sulphates is around $1100 \mathrm{~cm}^{-1}$. The peak at $1097 \mathrm{~cm}^{-1}$ exists, but the peaks that would represent typical sulphate copper corrosion products like brochantite, $\mathrm{Cu}_{4} \mathrm{SO}_{4}(\mathrm{OH})_{6}$, antlerite, $\mathrm{Cu}_{3}\left(\mathrm{SO}_{4}\right)(\mathrm{OH})_{4}$, or posnjakite, $\mathrm{Cu}_{4} \mathrm{SO}_{4}(\mathrm{OH})_{6} \cdot \mathrm{H}_{2} 0$, are not present in the spectra. So, it can be assumed that sulphate is present in an inorganic form on Sample 1 [24, 25].

The peak attributed to cuprite, $\mathrm{Cu}_{2} \mathrm{O}$, at around $625 \mathrm{~cm}^{-1}$ [24] is not observed on this sample or any of the other samples.

\section{Samples 2 and 3}

Sample 3 was the sample with the most expressed green colour with small presence of light blue hues. The surface layers used for the analysis of Sample 3 were prevalent in green. Sample 2 was also green, although its colour was uniform. The SEM image of the surface of Sample 3 showed two different structures presented in Fig. 5. The main difference between the two structures is that the composition of the second structure shows presence of tin, while the first composition does not. Sample 2 showed presence of only one composition that is similar to the composition in Point 1 with slightly higher content of calcium and lower content of aluminium and magnesium, indicating that the oxides composition is the only difference.

The FTIR spectra obtained on Samples 2 and 3 were very similar as can be seen in Fig. 6. Presence of malachite, $\mathrm{Cu}_{2} \mathrm{CO}_{3}(\mathrm{OH})_{2}$, was observed through various peaks. The bands at $\sim 1097$ and $\sim 1034 \mathrm{~cm}^{-1}$ are assigned to the $\mathrm{CO}$ symmetric and asymmetric stretching vibration. The two bands at $\sim 879$ and $\sim 821 \mathrm{~cm}^{-1}$ are attributed to the out of phase and in phase bending modes of carbonate in malachite [16]. The two bands clearly present at $\sim 3403$ and $\sim 3319 \mathrm{~cm}^{-1}$ are assigned to $\mathrm{O}-\mathrm{H}$ groups bound to intramolecular H-links [22], but as said earlier they cannot be used for distinguishing presence of different copper patinas.

EDS and XRF analysis showed presence of $\mathrm{Si}$ in these samples. The peak at $\sim 1097 \mathrm{~cm}^{-1}$ which is also attributed to malachite in combination with the rest of the peaks explained earlier indicated presence of Si-oxides. Presence of calcium carbonate in the form of vaterite is again presented by peaks at 1489,879 and $743 \mathrm{~cm}^{-1}$ on Sample 3, while in the spectrum of Sample 2 the peak at $712 \mathrm{~cm}^{-1}$ represents calcite [13]. $\mathrm{SnO}_{2}$ is presented by 533 and $480 \mathrm{~cm}^{-1}$. These samples showed presence of iron in the form of $\mathrm{Fe}_{2} \mathrm{O}_{3}$ with very small peaks at $786 \mathrm{~cm}^{-1}$ and $462 \mathrm{~cm}^{-1}$.

The broad peak at $1097 \mathrm{~cm}^{-1}$ could also be attributed to a sulphate compound. Although by EDS analysis sulphur was not found, XRF indicated its presence on both Samples 2 and 3. Upon observing the FTIR spectra it can be seen that the main peaks that present sulphate copper corrosion products are present [17, 24-26]. They show the internal vibrational modes of sulphate ions at 1097 and $1034 \mathrm{~cm}^{-1}$ (v3), $879 \mathrm{~cm}^{-1}$ (v1), $605 \mathrm{~cm}^{-1}$ (v4), the signals below $500 \mathrm{~cm}^{-1}$ are assigned to the $v 2$ internal mode of $\mathrm{SO}_{4}^{2-}$ and to $\mathrm{Cu}-\mathrm{O}$ vibrations, while the peaks at 3403 and $3319 \mathrm{~cm}^{-1}$ are attributed to $v(\mathrm{OH})$. Samples 2 and 3 were the only samples were sulphate patina was detected, and considering the intensity of the peaks compared to the peaks of malachite it was not the main type of patina on the samples. It is hard to distinguish which sulphate copper patina is present on bronze, brochantite, $\mathrm{Cu}_{4} \mathrm{SO}_{4}(\mathrm{OH})_{6}$, antlerite, $\mathrm{Cu}_{3}\left(\mathrm{SO}_{4}\right)(\mathrm{OH})_{4}$, or posnjakite, $\mathrm{Cu}_{4} \mathrm{SO}_{4}(\mathrm{OH})_{6} \cdot \mathrm{H}_{2} \mathrm{O}$, using FTIR, but posnjakite is not normally found on archaeological bronzes. On the other hand, brochantite mainly forms in exposed areas and it is a common corrosion product on bronze sculptures located in urban areas where atmospheric sulphur dioxide is present [27]. On bronze objects exposed to freshwater antlerite is most commonly found [5]. The presence of sulphate patina does not exclude presence of inorganic sulphates that were found on Sample 1.

\section{Sample 4}

Sample 4 has a blackish colour, as can be seen in Fig. 2 . The main colour is not green/blue pigmented, so it is expected that this sample is not a sample where copper corrosion products prevail. The SEM image obtained on Sample 4 is presented in Fig. 7. It shows presence of two different structures pointed by numbers 1 and 2 . The structure in Point 1 has a rougher structure, while the structure in Point 2 is smoother. EDS analysis were performed in these two points and the results are also 

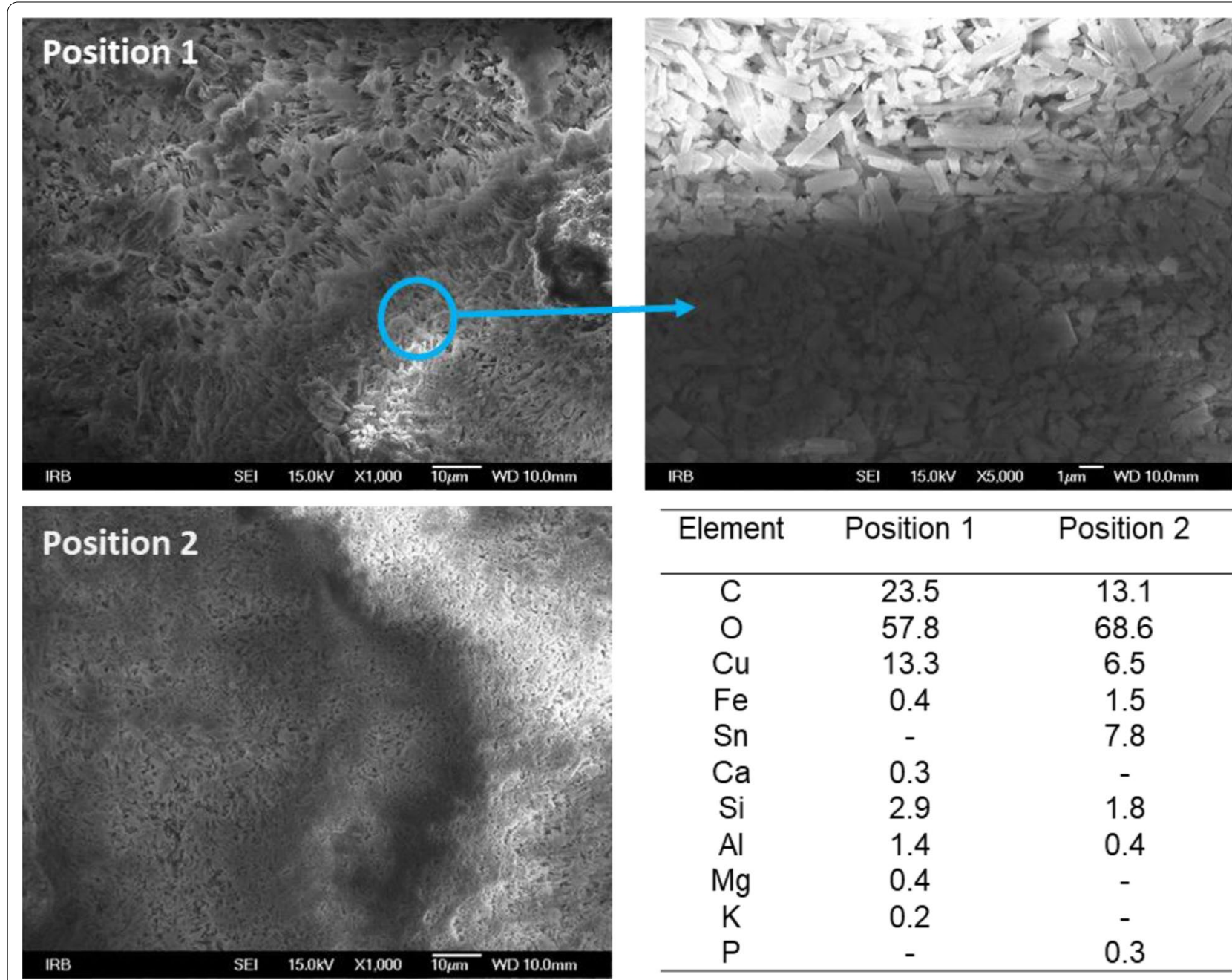

\begin{tabular}{ccc}
\hline Element & Position 1 & Position 2 \\
\hline $\mathrm{C}$ & 23.5 & 13.1 \\
$\mathrm{O}$ & 57.8 & 68.6 \\
$\mathrm{Cu}$ & 13.3 & 6.5 \\
$\mathrm{Fe}$ & 0.4 & 1.5 \\
$\mathrm{Sn}$ & - & 7.8 \\
$\mathrm{Ca}$ & 0.3 & - \\
$\mathrm{Si}$ & 2.9 & 1.8 \\
$\mathrm{Al}$ & 1.4 & 0.4 \\
$\mathrm{Mg}$ & 0.4 & - \\
$\mathrm{K}$ & 0.2 & - \\
$\mathrm{P}$ & - & 0.3 \\
\hline
\end{tabular}

Fig. 5 SEM image of two different positions on Sample 3 and elemental composition in atomic-\% obtained on the two positions by point analysis

presented in Fig. 7. It is clear that in Point 1 iron is a dominant element, while in point 2 silicon is.

FTIR results obtained on Sample 4 show clear peaks only in the region up to $1500 \mathrm{~cm}^{-1}$ presented on Fig. 8 . Metal oxides of various types have bands from the metal-O-metal group that can absorb throughout the $800-200 \mathrm{~cm}^{-1}$ region [21]. As stated earlier, various metal-oxides are expected to be present according to the composition of the traces of river Kupa. According to the EDS analysis presence of $\mathrm{Al}_{2} \mathrm{O}_{3}, \mathrm{MgO}$ and $\mathrm{NaO}$ is most likely and the other peaks in this region are most likely attributed to their presence. In the spectrum of Sample 4 the bands representing $\mathrm{Fe}_{2} \mathrm{O}_{3}$ are observed as on the other samples with peaks at 796 and $468 \mathrm{~cm}^{-1}$.

EDS showed significant amount of $\mathrm{Si}$ in the sample. The band at around $\sim 1000 \mathrm{~cm}^{-1}$ that presents silica is not present on this sample, but the bands at $1050-1000 \mathrm{~cm}^{-1}$ (strong) and at $540-440 \mathrm{~cm}^{-1}$ (medium) presenting inorganic silicates are present in the spectra.

The broad wide peak at $\sim 1001 \mathrm{~cm}^{-1}$ is much more expressed in this spectrum compared to the spectra of Samples 1-3 and it again indicates presence of $\mathrm{SO}_{4}$ vibrations. As in the case of Sample 1 there are no peaks indicating copper sulphate patina, so it can be assumed that the inorganic sulphates are present here as well.

The spectrum of Sample 4, unlike the spectra of Sample 1 indicates that calcium carbonate is present in the form of calcite rather than vaterite. This is due to only one band at $v 3-418, v 2-77$ and the peak at $v 4-$ $695 \mathrm{~cm}^{-1}$ which is specific for calcite [13].

Sample 4 was the only sample that did not show presence of tin on its surface. 


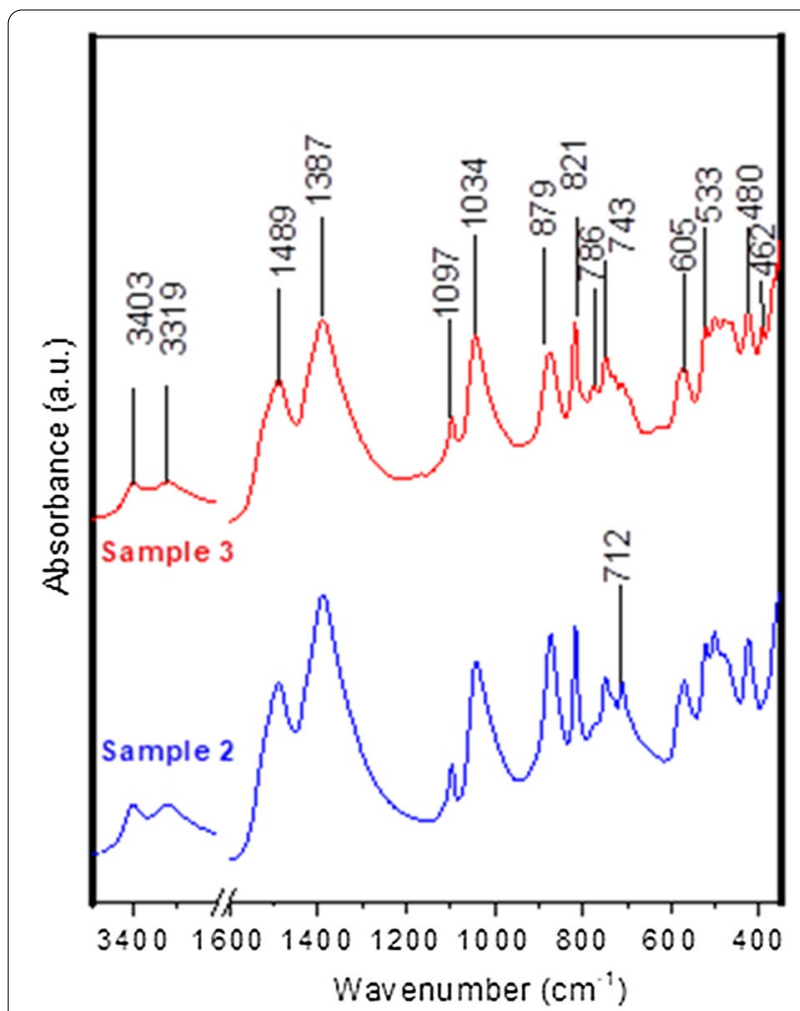

Fig. 6 FTIR spectra observed on Samples 2 and 3

\section{Samples 5 and 6}

Samples 5 and 6 seem to have a similar appearance by the bare eye and this can be seen from the images in Fig. 2 . They are both multi-coloured. The SEM results showed a similar structure as can be seen in Fig. 9a and the FTIR spectra obtained on the two samples are also very similar as can be seen on Fig. 9b. On the other hand, EDS analysis (Table 2) on the two samples showed quite different results. It seemed each measured point had a different composition as can be seen in Table 2. Sample 5 showed a significant amount of iron and copper while Sample 6 showed higher content of tin and silicon, depending on the position. Also, the content of carbon in Sample 6 is significantly higher than on the other examined samples. Sample 6 also showed very small content of copper indicating that just like in the case of Sample 4 in this sample copper corrosion products do not prevail. As for Sample 5 the copper content is somewhat higher.

The FTIR spectra in the metal-oxide region, i.e. at lower wavenumbers, show very many peaks that are close to each other. It can be assumed that some of the peaks representing different metal-oxides are overlapping. When we look at EDS results, we can assume presence of different metal oxides. The peak at $1002 \mathrm{~cm}^{-1}$ presents $\mathrm{Si}-\mathrm{O}$ bands, while the peak at $796 \mathrm{~cm}^{-1}$ represents quartz, i.e. $\mathrm{SiO}_{2}$. The peak at $796 \mathrm{~cm}^{-1}$ overlaps with the peak of $\mathrm{SnO}_{2}$ which is also indicated by peaks at 527 and $465 \mathrm{~cm}^{-1}$. The peak at 527 is also presenting $\mathrm{Fe}_{2} \mathrm{O}_{3}$. The two peaks at around 1571 and $1375 \mathrm{~cm}^{-1}$ indicate presence of carbonate in some form. The peaks at 796, 750 and $1375 \mathrm{~cm}^{-1}$ indicate presence of malachite, although it is clear from the size of the peaks that its quantity is small as on sample 4 . The peak at $778 \mathrm{~cm}^{-1}$ presents overlapping peaks presenting both quartz and malachite.

\section{Discussion}

The results have shown that the kettle alloy contains approximately $9.5 \%$ of tin. Thus, it is made of a low-tin bronze (containing up to $14 \mathrm{wt} \%$ tin). Alloys that contain more than about $14 \mathrm{wt} \%$ tin (high-tin bronzes) are brittle and hard. On the other hand, low-tin bronzes are usually

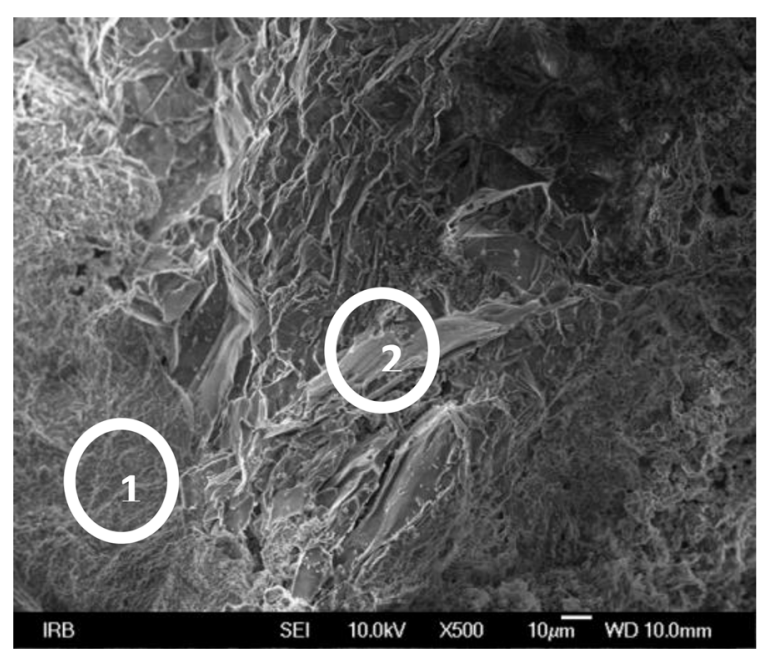

\begin{tabular}{ccc}
\hline Element & Point 1 & Point 2 \\
\hline $\mathrm{C}$ & 14.9 & 4.5 \\
$\mathrm{O}$ & 59.2 & 64.4 \\
$\mathrm{Cu}$ & 5.4 & 0.6 \\
$\mathrm{Fe}$ & 10.9 & 2.0 \\
$\mathrm{Ca}$ & 1.8 & 0.2 \\
$\mathrm{Si}$ & 5.0 & 28.3 \\
$\mathrm{Al}$ & 0.9 & - \\
$\mathrm{Mg}$ & 1.3 & - \\
$\mathrm{S}$ & 0.3 & - \\
$\mathrm{P}$ & 0.4 & - \\
\hline
\end{tabular}

Fig. 7 SEM image of Sample 4 and elemental composition in atomic-\% obtained by EDS analysis on the two points marked on the SEM image 


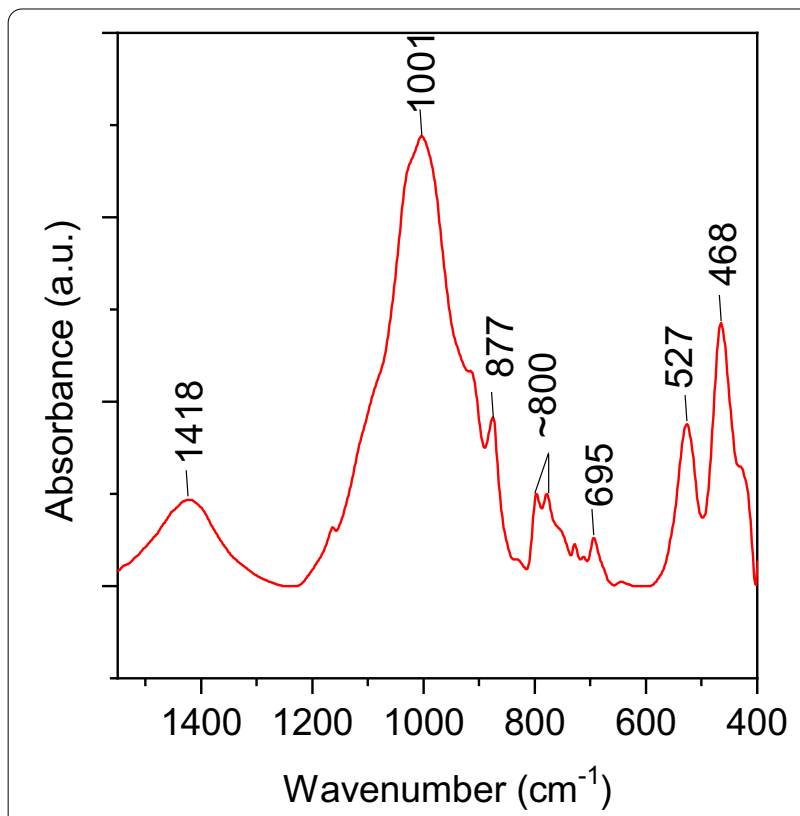

Fig. 8 FTIR spectrum obtained on Sample 4

single-phase alloys and can be shaped by hammering and thus they are suitable for the embossing technique which was used to make the kettle [6]. Aluminium and nickel were added to the alloy in order to reinforce the structure of the alloy, while calcium was added to reduce the melting point which greatly facilitates the processing and serves as a deoxidizer for copper [6].

Presence of iron in a copper alloy is not common since pure iron is generally not added to bronze, yet it is occasionally found. For example, Pronti et al. [28] reported that $0.2-0.4$ wt-\% of iron was found in Greek and Roman coins from Pompei or Fernandes et al. [29] investigated 44 Roman copper-alloyed artefacts from a location close to Utrect in The Netherlands and reported that in the majority of the artefacts above $5 \%$ of iron was present. Iron in the alloy that the kettle was made from may originate from impurities of the raw material for making the object. Also, it is possible that the same furnace was used for different metal alloys so impurities can originate from there as well.

The kettle was an object for everyday use, and the damage began to form while it was still in function. After that, it was buried for almost 2000 years, which led to creation of various aerobic corrosion products and production of beautiful patina which was intermittently interrupted by active products of corrosion. After excavation, drastic and sudden changes in environmental conditions, especially increase of oxygen concentration, induced restarting and accelerating corrosion of the bronze substrate $[4,7]$ and new layers of corrosion products were created on the kettle. There were no interventions on the kettle after it was excavated until the moment it arrived at the Workshop, which means it had been waiting for restoration while being exposed to atmospheric conditions of the Museum's depot for more than 50 years.

Table 3 presents the different compounds that were found present on the examined samples. The characteristic green-blue appearance of the patina layer is due to the colour forming $\mathrm{Cu}(\mathrm{II})$-ion in the outer patina layer which needs to be $12 \pm 2 \mu \mathrm{m}$ to fully cover the inner oxide layer [2]. The patina on the kettle was identified as malachite, $\mathrm{Cu}_{2} \mathrm{CO}_{3}(\mathrm{OH})_{2}$. It was formed over most parts of the object's surface, but it is not everywhere in equal amount and thickness. Figure 10 presents the presence of malachite on the kettle. The schematic image was made by isolating only the colour of the malachite from the image of the kettle. It is the corrosion product that was created on the surface of the kettle while the object was buried in the mud of the Kupa River. It was the first corrosion
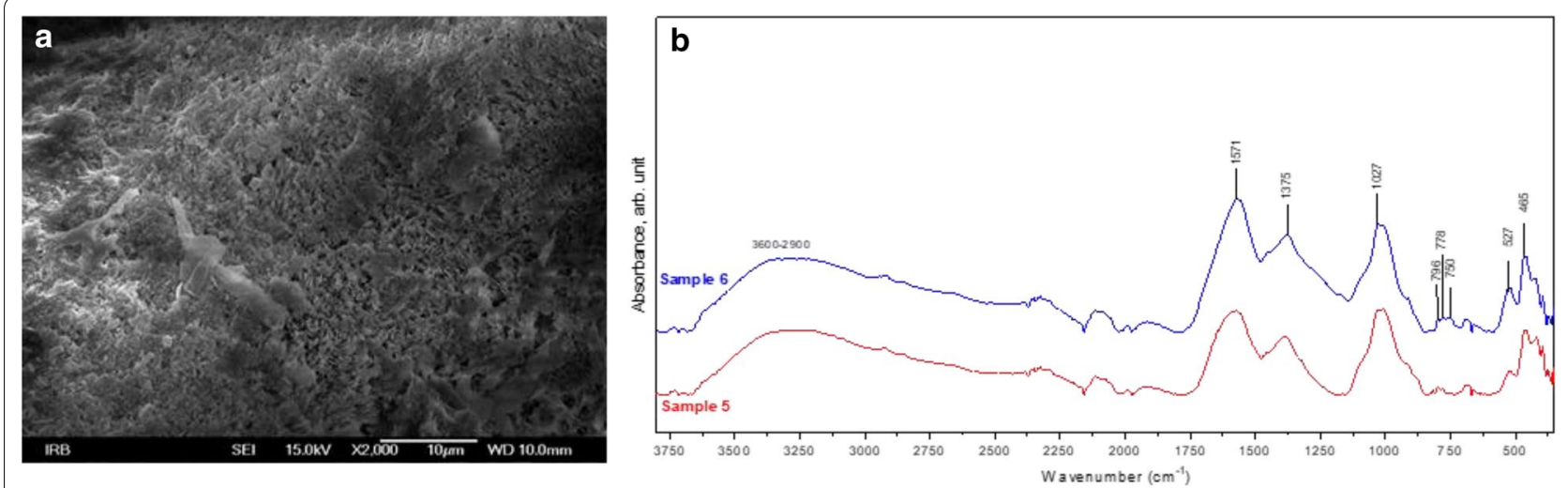

Fig. 9 a Typical SEM image of Samples 5 and 6, and $\mathbf{b}$ FTIR spectra observed on the samples 
Table 2 Elemental composition in atomic-\% obtained by EDS analysis on Samples 5 and 6 in various positions

\begin{tabular}{|c|c|c|c|c|c|}
\hline \multirow[t]{2}{*}{ Element } & \multicolumn{2}{|l|}{ Sample 5} & \multicolumn{3}{|l|}{ Sample 6} \\
\hline & Position 1 & Position 2 & Position 1 & Position 2 & Position 3 \\
\hline C & 22.0 & 23.7 & 47.9 & 52.8 & 66.1 \\
\hline $\mathrm{O}$ & 58.5 & 55.5 & 42.8 & 39.3 & 29.7 \\
\hline $\mathrm{Cu}$ & 14.7 & 8.0 & 0.6 & 1.7 & 2.1 \\
\hline $\mathrm{Fe}$ & 1.3 & 9.6 & 0.3 & 0.7 & 0.5 \\
\hline Sn & - & 0.6 & - & 4.1 & - \\
\hline $\mathrm{Ca}$ & 0.4 & 0.3 & 0.7 & 0.8 & 0.9 \\
\hline $\mathrm{Si}$ & 1.9 & 1.5 & 4.4 & 0.3 & 0.4 \\
\hline $\mathrm{Al}$ & 0.8 & - & 2.3 & - & 0.2 \\
\hline $\mathrm{Mg}$ & 0.4 & - & 0.6 & - & - \\
\hline S & 0.1 & 0.4 & 0.2 & 0.2 & 0.1 \\
\hline$P$ & - & 0.6 & - & 0.2 & - \\
\hline
\end{tabular}

product that covered the surface during this period. When copper alloys are buried in damp places, they tend to form green corrosion products such as georgite, which forms before malachite. Also, the blue-coloured mineral azurite may appear, however, in little less humid places, but it is also prone to creation under buried conditions [6]. Neither georgite or azurite were found in our case.

The samples had several other compounds present on the surface. Presence of $\mathrm{SnO}_{2}$ which is black in colour in the form of cassiterite was observed on most of the samples. Tin oxide is a common corrosion product in all tin bronzes in various environments. Among others, it forms when tin is exposed to fire in presence of air [30]. Since this type of kettle was used for cooking part of the present $\mathrm{SnO}_{2}$ was formed while it was used to prepare food on open fire. Thus, we can assume that some of the $\mathrm{SnO}_{2}$ was created before the kettle was buried in the river mud and remained on the kettle as it is not soluble in water. We assumed that beneath malachite a layer of cuprite, $\mathrm{Cu}_{2} \mathrm{O}$, is present. Such a layer when formed in atmospheric conditions is fully attained at thickness of
$0.8 \pm 0.2 \mu \mathrm{m}$ [2]. We were not able to identify cuprite on the kettle. This was either because the layer was well covered by other compounds or because $\mathrm{SnO}_{2}$ was present in a large amount.

$\mathrm{Si}-\mathrm{OH}, \mathrm{SiO}_{2}$ and $\mathrm{SiO}$, as well as $\mathrm{CaCO}_{3}$, were also observed on most samples. We can conclude that they are sediments from the river Kupa. These layers were present over malachite and they are a result of longer exposure to the river environment. These $\mathrm{Si}$ and $\mathrm{Ca}$ based layers have a large volume and are porous, thus sediment like soil and stones located in the riverbed in the proximity of the object were captured in the corrosion products. All other trace elements that were found can also originate from the structure of the sediment in Kupa River or be part of the corrosion products produced while the object was buried [10].

The three samples (Samples 4, 5 and 6) which were not predominant in green colour, but rather brown/ blackish showed presence of a higher quantity of ferric oxide, $\mathrm{Fe}_{2} \mathrm{O}_{3}$. Iron does not have to originate from the bronze alloy. The assumption is that the bronze kettle had a ferrous alloy rim and a handle which was attached while forging, so there was no need to solder it

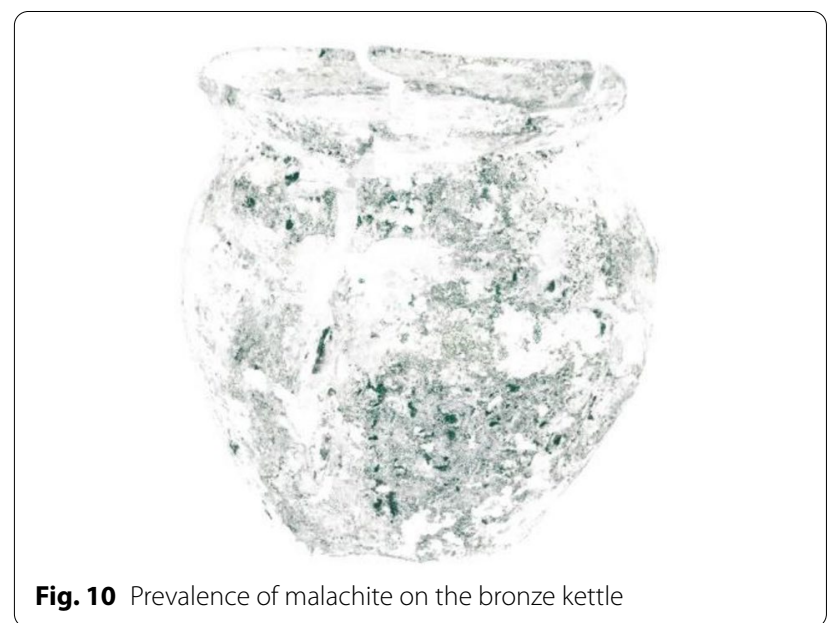

Table 3 Overview of the different compound's presence on the examined samples

\begin{tabular}{|c|c|c|c|c|c|c|}
\hline Sample & 1 & 2 & 3 & 4 & 5 & 6 \\
\hline Malachite, $\mathrm{Cu}_{2}\left(\mathrm{CO}_{3}\right)(\mathrm{OH})_{2}$ & $\mathrm{H}$ & $\mathrm{H}$ & $\mathrm{H}$ & $L$ & $L$ & $\mathrm{~L}$ \\
\hline Cassiterite, $\mathrm{SnO}_{2}$ & $\mathrm{H}$ & $\mathrm{H}$ & $\mathrm{H}$ & - & - & $\mathrm{L}$ \\
\hline Calcium carbonate, $\mathrm{CaCO}_{3}$ & $H$ & $H$ & $H$ & $L$ & - & - \\
\hline Ferric oxide, $\mathrm{Fe}_{2} \mathrm{O}_{3}$ & $L$ & $L$ & $L$ & $\mathrm{H}$ & $\mathrm{H}$ & $H$ \\
\hline Inorganic sulphates & $L$ & $L$ & $L$ & $\mathrm{H}$ & - & - \\
\hline Sulphate patina & - & $L$ & $L$ & - & - & - \\
\hline $\mathrm{SiO}_{2}$ & $L$ & - & - & - & $\mathrm{H}$ & $\mathrm{H}$ \\
\hline Si-oxides & - & $L$ & $\mathrm{~L}$ & $\mathrm{H}$ & - & - \\
\hline
\end{tabular}

$H$ high content, $L$ low content 
to the kettle. The sample was taken at the top of the kettle, where the handle would have been located. Unfortunately, no part of the handle was preserved, however, most of the kettles found in that period had one. Part of the $\mathrm{Fe}_{2} \mathrm{O}_{3}$ creation may have been caused by the degradation of the ferrous alloy handle. As ferrous alloy degraded, ferrous corrosion products were created locally. Vicinity of ferrous objects such as a rim or some other object can also be source of $\mathrm{Fe}$ oxides formation, but there was no evidence if other ferrous objects were found in such vicinity of the kettle itself. This would explain the inability to form malachite below this layer of corrosion products, since galvanic corrosion occurred and the iron dilution rapidly accelerated, while in these areas copper was cathodically protected.

Below two samples a layer of malachite was found: Sample 5 is brown in colour and Sample 6 is black. Analyses have shown that these are $\mathrm{Fe}, \mathrm{Sn}$ and $\mathrm{Si}$ oxides. The brown sample (Sample 5) showed a greater content of iron, and it can be concluded that it consists mainly of iron oxides. The black surface layers (Sample 6) indicated presence of tin oxides, as well the presence of $\mathrm{SiO}$. The areas on the kettle where Sample 5 was taken had brown surface layers. The layer of malachite beneath the brown surface layers is slightly thinner, i.e. on every part of the metal surface on which a stable surface layer is not formed, has a possibility of later oxidation to occur when exposed to air, and the result is the creation of new corrosion products after excavation of the object. On Sample 6 tin oxide prevails which explains the black colour of the surface layers. In this case these oxides were also formed after the formation of malachite, since by removing the powdered black coloured product underneath the already formed green malachite layer was found. On the same sample, compounds such as $\mathrm{Fe}_{2} \mathrm{O}_{3}$ were found and the presence of carbonates was detected.

Sulphur compounds exist in highest amount in Sample 4 (XRF results), and in somewhat smaller amounts in Samples 1, 2 and 3, and smallest amounts are found in Samples 5 and 6. The peak representing sulphate (ca. $1100 \mathrm{~cm}^{-1}$ ) is clearly observable on Samples $1-3$ while on sample 4 it is observable as a shoulder peak partially overlapped by the very strong silica peak (ca. $1000 \mathrm{~cm}^{-1}$ ). We assume that sulphur presence on the surface of bronze is from a newer date since the city Sisak was one of the main industrial cities in Croatia with very high air pollution in the recent centuries. Thus, these surface layers were created after excavation, on parts of the kettle's surface which was not completely protected by other surface layers.

\section{Conclusions}

The kettle is made of low-tin bronze. The alloy has $9.5 \%$ tin with addition of aluminium, calcium, nickel and iron in concentrations bellow $0.5 \%$. Such low-tin bronzes were used for manufacturing by embossing because of their resistance to mechanical and corrosion resistance. Addition of calcium reduced the melting point of the alloy, while addition of aluminium and nickel can be attributed to the reinforcement of the bronze.

The layers of corrosion products were formed according to the conditions the object was exposed to. The kettle was probably used for preparing food and in this case exposed to fire. Thus, the first product that would have formed on the surface would be $\operatorname{tin}(\mathrm{II})$ oxide, $\mathrm{SnO}_{2} \cdot \mathrm{SnO}_{2}$ is insoluble in water and the oxides stayed on the surface during its exposure to water in the Kupa river. The kettle was buried for almost two millennia in the mud of the Kupa River. Since no chlorides are present in such waters, the subject has remained fairly well preserved. The limited oxygen presence and very humid conditions in which the object was found almost completely covered it with a malachite layer that gave it a greenish-blue colour. Surface layers, such as iron oxides most likely formed by dissolving the iron rim and handle which have not been preserved until today, as they have completely degraded, probably while the kettle was still underground.

The item was excavated in the 1960s and stored in a museum depot. After excavation, the object came again in an oxygen-enriched and polluted atmosphere and it developed additional layers of corrosion products over the malachite layer. The analysed samples showed that the upper layers are mainly iron oxides and tin oxides, which are brown and black. Also, calcium carbonate and silicon oxides are present on the kettle. They are compounds that remained trapped in the corrosion products from the mud of the Kupa river. Sulphur presence was detected on all samples, mostly in the form of sulphates, both inorganic and as patina. These compounds were also most likely formed last during exposure to the polluted atmosphere in the city of Sisak.

\section{Abbreviations \\ XRF: X-Ray Fluorescence; FTIR: Fourier transform infrared spectroscopy; ATR : Attenuated total reflection; SEM: Scanning electron microscopy; FE-SEM: Field emission scanning electron microscope; EDS: X-ray energy dispersive spectroscopy.}

\section{Acknowledgements}

The authors would like to thank Sisak Municipal Museum for providing the object of this matter for investigation of surface layers and corrosion products development as well as for the conservation-restoration treatment. The authors are very grateful to dr. sc. Damir Kralj for access to FTIR.

Authors' contributions

MK and KM conceived this research. MK performed the conservation-restoration operations of the object and sampling. KM organized the analytical 
investigations and interpretation of analysis. MS interpreted the results of analysis according to whereabouts of the object. VD performed XRF analysis. NM performed FTIR analysis.

\section{Funding}

The presented work was not funded by any research project.

\section{Availability of data and materials}

The raw data presented in this manuscript are in the possession of the authors. Since the amount of data is large the authors will present the data upon request.

\section{Ethics approval and consent to participate}

Not applicable.

\section{Consent for publication}

Not applicable.

\section{Competing interests}

The authors declared that there is no conflict of interest.

\section{Author details}

${ }^{1}$ Art and Restoration Department, Workshop for conservation and restoration of metal, University of Dubrovnik, Ćira Carića 2, Dubrovnik, Croatia. ${ }^{2}$ Ruđer Bošković Institute, Division of Materials Chemistry, Laboratory for Precipitation Processes, Bijenička c. 54, Zagreb, Croatia. ${ }^{3}$ Department for Conservation and Restoration, University of Zagreb, Academy of Fine Arts, Zamenhofova 14, Zagreb, Croatia. ${ }^{4}$ Ruđer Bošković Institute, Division of Materials Chemistry, Radiation Chemistry and Dosimetry Laboratory, Bijenička c. 54, Zagreb HR-10000, Croatia.

Received: 2 October 2020 Accepted: 16 January 2021

Published online: 26 January 2021

\section{References}

1. Cronyn JM, Robinson WS. Organic Materials. In: The Elements of Archaeological Conservation. London: Routledge; 1990. pp. 238-95.

2. Leygraf C, Chang T, Herting G, Odnevall I, Wallinder. The origin and evolution of copper patina colour. Corr Sci. 2019;157:337-46. https://doi. org/10.1016/j.corsci.2019.05.025.

3. Graedel TE, Nassau K, Franey JP. Copper patinas formed in the atmosphere-I. Introduction. Corr Sci. 1987;27(7):639-57. https://doi. org/10.1016/0010-938X(87)90047-3.

4. Wu J, Wang J. The effects of UV and visible light on the corrosion of bronze covered with an oxide film in aqueous solution. Corr Sci. 2019;154:144-58. https://doi.org/10.1016/j.corsci.2019.01.009.

5. Schweizer F. Bronze Objects from Lake Sites: from Patina to 'Biography' In: Ancient and Historic Metals: Conservation and Scientific Research. Proceedings of a Symposium organized by the J. Paul Getty Museum and the Getty Conservation Institute in November 1991. 1994. p. 33-50. (Sect. 1: http://www.getty.edu/conservation/publications_resources/ pdf_publications/ancientmetals.html).

6. Selwyn L. Metals and Corrosion: A Handbook for the Conservation Professional, Canadian Conservation Institute, Ottawa, Canada.

7. Muresan L, Varvara S, Stupnišek-Lisac E, Otmačić H, Marušić K, HorvatKurbegović S, Robbiola L, Rahmouni K, Takenouti H. Protection of bronze covered with patina by innoxious organic substances. Electrochim Acta. 2007;52:7770-9. https://doi.org/10.1016/j.electacta.2007.02.024.

8. Scott DA. Copper and bronze in art: corrosion, colorants, conservation. Los Angeles: The Getty Conservation Institute; 2002.

9. Robbiola L, Portier R. A global approach to the authentication of ancient bronzes based on the characterization of the alloy-patina-environment system. J Cult Herit. 2006;7:1-12. https://doi.org/10.1016/j.culher.2005.11.001.

10. Bilinski $\mathrm{H}$. Weathering of sandstones studied from the composition of stream sediments of the Kupa River (Croatia). Mineral Mag. 2008;72(1):236. https://doi.org/10.1180/minmag.2008.072.1.23.

11. Nunez L, Reguera E, Corvo F, Gonzalez E, Vazquez C. Corrosion of copper in seawater and its aerosols in a tropical island. Corr Sci. 2005;47:461-84. https://doi.org/10.1016/j.corsci.2004.05.015.
12. Chiavari C, Colledan A, Frignani A, Brunoro G. Corrosion evaluation of traditional and new bronzes for artistic castings. Mater Chem Phys. 2006;95:252-9. https://doi.org/10.1016/j.matchemphys.2005.06.034.

13. Wang $Y$, Moo YX, Chen C, Gunawan $P, X u$ R. Fast precipitation of uniform $\mathrm{CaCO}_{3}$ nanospheres and their transformation to hollow hydroxyapatite nanospheres. J Colloid Interface Sci 352 (2010) 393-400. https://doi. org/10.1016/j.jcis.2010.08.060.

14. Ni M, Ratner BD. Differentiating calcium carbonate polymorphs by surface analysis techniques - an XPS and TOF-SIMS study, Surf. Interface Anal 40 (2008) 1356-61. https://doi.org/10.1002/sia.2904.

15. Al Omari MMH, Rashid IS, Qinna NA, Jaber AM, Badwan AA. Calcium Carbonate, Profiles Drug Subst. Excip Relat Methodol. 2016;41:31-132. https ://doi.org/10.1016/bs.podrm.2015.11.003.

16. Frost RL, Martens WN, Rintoul L, Mahmutagic E, Kloprogge JT. Raman spectroscopic study of azurite and malachite at 298 and 77K. J Raman Spectrosc. 2002;33(4):252-9. https://doi.org/10.1002/jrs.848.

17. Malvault JY, Lopitaux J, Delahaye D, Lenglet M. Cathodic reduction and infrared reflectance spectroscopy of basic copper(II) salts on copper substrate. J Appl Electrochem. 1995;25:841-5. https://doi.org/10.1007/ bf00772202.

18. Khalaf HA, El-Madani EA, Mansour SE. Surface properties of copper-modified tin oxide catalysts. Glob J Inorg Chem. 2011;2/2:102-9.

19. Luo W, Song G, Huc Y, Chen D. Tentative determination of a special bronze material by multiple technological test on a xuan-liu dagger-axe from the Xujialing Site, the Eastern Zhou period, Henan Province, China. J Cultural Heritage. 2020. https://doi.org/10.1016/j.culher.2020.06.016.

20. Chukanov NV, Chervonnyi AD. Infrared Spectroscopy of Minerals and Related Compounds, Springer Mineralogy; 2016. ISBN 978-3-319-25347-3.

21. Colthup NB, Daly LH, Wiberley SE, Compounds Containing Boron, Silicon, Phosphorus, Sulfur, or Halogen, in: Introduction to Infrared and Raman Spectroscopy, ${ }^{3 r d}$ Edition, Academic Press, Inc., Waltham, 1990, p. 355-385.

22. Silva CE, Silva LP. Diffuse reflection FTIR spectral database of dyes and pigments. Anal Bioanal Chem. 2006;386:2183-91. https://doi.org/10.1007/ s00216-006-0865-8.

23. Jahagirdar AA, Dhananjaya N, Monika DL, Kesavulu CR, Nagabhushana H, Sharma SC, Nagabhushana BM, Shivakumara C, Rao JL, Chakradhar RPS. Structural, EPR, optical and magnetic properties of alpha- $\mathrm{Fe}_{2} \mathrm{O}_{3}$ nanoparticles. Spectrochim Acta A. 2013;104:512-8. https://doi.org/10.1016/j. saa.2012.09.069.

24. Di Carlo G, Giuliani C, Riccucci C, Pascucci M, Messina E, Fierro G, Lavorgna M, Ingo GM. Artificial patina formation onto copper-based alloys: Chloride and sulphate induced corrosion processes. Appl Surf Sci. 2017:421A:120-7. https://doi.org/10.1016/j.apsusc.2017.01.080.

25. Kiefer J, Stärk A, Kiefer A, Glade H, Infrared spectroscopic analysis of the inorganic deposits from water in domestic and technical heat exchangers. Energies. 11(4) (2018) 798. https://doi.org/10.3390/en11040798.

26. Zaffino C, Guglielmi V, Faraone S, Vinaccia A, Bruni S. Exploiting external reflection FTIR spectroscopy for the in-situ identification of pigments and binders in illuminated manuscripts. Brochantite and posnjakite as a case study. Spectrochim Acta A. 2015;136:1076-1085. https://doi.org/10.1016/j. saa.2014.09.132

27. Leygraf C, T. E. Graedel. Atmospheric corrosion. New York: Wiley-Interscience; 2000. ISBN 0471372196.

28. Pronti L, Felici AC, Alesiani M, Tarquini O, Bracciale MP, Santarelli ML. Characterisation of corrosion layers formed under burial environment of copper-based Greek and Roman coins from Pompeii Lucilla. Appl Phys A. 2015;121:59-68. https://doi.org/10.1007/s00339-015-9351-5.

29. Fernandes R, van Os BJH, Huisman HDJ. The use of Hand-Held XRF for investigating the composition and corrosion of Roman copper-alloyed artefacts. Herit Sci. 2013;1:30. https://doi.org/10.1186/2050-7445-1-30.

30. Wiberg E, Wiberg N, Holleman AF. Inorganic Chemistry. San Diego: Academic Press; 2001.

\section{Publisher's note}

Springer Nature remains neutral with regard to jurisdictional claims in published maps and institutional affiliations. 